\title{
Pediatric Rheumatology Collaborative Study Group - over four decades of pivotal clinical drug research in pediatric rheumatology
}

\author{
Hermine I. Brunner ${ }^{1 *}$ (D), Lisa G. Rider ${ }^{2}$, Daniel J. Kingsbury ${ }^{3}$, Dominic Co ${ }^{4}$, Rayfel Schneider ${ }^{5}$, Ellen Goldmuntz ${ }^{6}$,
} Karen B. Onel ${ }^{7}$, Edward H. Giannini ${ }^{1}$, Daniel J. Lovell ${ }^{1}$ and for the PRCSG Advisory Council

\begin{abstract}
Importance: Specialized research networks are essential to achieve drug approvals for rare pediatric diseases. Such networks help realize the potential of global legislation enacted upon the recognition that most children are treated with drugs whose most beneficial dose and regimen have not been established in pediatric patients. The Pediatric Rheumatology Collaborative Study Group (PRCSG) is a North American clinical trials network that is specialized in the performance of clinical trials of new therapies for pediatric populations with rheumatic diseases. This review provides an overview of the strategies employed by this research network to achieve drug and biologic approvals for children with pediatric rheumatic diseases, particularly juvenile idiopathic arthritis.

Observations: Clinical trial conduct in rare pediatric diseases has required global recruitment. Supported or led by the PRCSG, highly responsive, validated, composite measures have been established to assess drug efficacy. For pediatric orphan diseases with high disease burdens, specialized investigative sites and study designs are needed to complete adequately powered trials at the high standard necessary to enable drug labeling by regulatory agencies. Novel trial designs have been utilized for more efficient testing of innovative drug candidates. All these have been developed or co-developed by the PRCSG research network.
\end{abstract}

Conclusions and relevance: Specialized research networks in pediatric rheumatology, such as the PRCSG, have changed the landscape of available therapies and improved overall disease outcomes for children with pediatric rheumatic diseases.

Keywords: Clinical trials, JIA, PRCSG, Drug approvals, Pediatrics, Networks

\section{Background}

There remains a profound unmet medical need for the effective and safe treatment of pediatric rheumatic diseases. As these diseases are rare, highly specialized and experienced research networks are best suited to support therapeutic trials of new drug compounds. The Pediatric Rheumatology Collaborative Study Group (PRCSG) has an over 40-year long track record of successfully

\footnotetext{
* Correspondence: Hermine.brunner@cchmc.org

${ }^{1}$ Division of Rheumatology, Cincinnati Children's Hospital Medical Center \& Cincinnati Children's Research Foundation, MLC 4010, Cincinnati, OH 45229, USA

Full list of author information is available at the end of the article
}

supporting the design, conduct, analysis, and publication of such therapeutic trials in close collaboration with industry sponsors. The PRCSG has intensely focused on ensuring that clinical trial designs have scientific rigor, are practical for enrollment by pediatric rheumatologists, and acceptable to families of children with pediatric rheumatic diseases. Studies conducted in collaboration with the PRCSG changed the landscape of pediatric rheumatology care over the past decades. The objective of this review is to highlight the history of the PRCSG, including approaches developed and used by the research network that made effective therapies available to children with pediatric rheumatic diseases. 
Food and Drug Administration regulations for drugs for children with pediatric rheumatic diseases

The Food and Drug Administration (FDA) is the federal agency charged with overseeing drug manufacturing, labeling, advertisement, and safety of medications and biological products [1] in the United States (U.S.). The Food, Drug, and Cosmetic Act (FD\&C Act) requires that there is "substantial evidence," resulting from "adequate and well controlled investigations" to demonstrate that a new drug "will have the effect it purports or is represented to have under the conditions of use prescribed, recommended, or suggested in the proposed labeling." New drug and biologic applications are submitted to and reviewed by the FDA for potential approval for marketing in the U.S [2].

Activism by professional organizations, families, and networks, such as the PRCSG, resulted in legislation that markedly changed the landscape of drug therapy for children. In the U.S., medication labeling and drug studies are governed largely by two sections of the FD\&C Act: section 505A pertains to The Best Pharmaceuticals for Children Act (BPCA) [3] and section 505B to the Pediatric Research Equity Act (PREA) [4], respectively. Together these two laws encourage and/or require drug companies to study their products in children [5]. PREA necessitates new drugs and biologic therapies to be studied in children, if there is a pediatric disease that is similar to a non-orphan disease occurring in adults, and it is likely that the new agent will be used in children. The FDA considers juvenile idiopathic arthritis (JIA) with polyarticular joint involvement the pediatric correlate of adult rheumatoid arthritis (RA) [6]. BPCA provides pharmaceutical manufacturers with 6 months of additional market exclusivity after the completion of pediatric drug studies that have been done at request of the FDA. There is no exclusion for orphan diseases, but biologic therapies are not covered. The FDA Safety and Innovation Act (FDASIA) made PREA and BPCA permanent, which was important because, prior to 2012, PREA and BPCA were merely regulations intended to be in place for a limited time. Almost all stakeholders involved, including leaders of the PRCSG, asserted that permanence of PREA and BPCA was an important aspect for future drug development for children. Together, these laws resulted in the labeling of more than 600 products for pediatric indications, 149 of which occurred since the passage of FDASIA [7]. A recent review by the European Medicines Agency (EMA) and FDA confirmed that the existence of pediatric research networks, such as the PRCSG, is of utmost importance to realize the potential of this new pediatric legislation [2, 8].

Integration of pediatric planning and exclusivity requests are now a part of regular new drug and biologic product development programs at pharmaceutical companies. Key documents to be developed include the initial Pediatric Study Plan (iPSP) for submission to and approval by the Center for Drug Evaluation and Research (CDER) or the Center for Biologics Evaluation and Research (CBER) at FDA [9].

Importantly, the EMA passed similar legislation concerning pediatric drug testing and approval. Like the iPSP, a Pediatric Investigational Plan (PIP) must be submitted to the Paediatric Committee (PDCO), EMA's scientific committee that is responsible for activities concerning medicine testing in children. PDCO oversees the labeling of such medicines in the European Union. One difference between the U.S. and the European legislation is that PIP submission to PDCO takes place by the end of Phase I development in adults, while iPSP submission to FDA is expected to occur later around the end of Phase II development in adults.

It has been a long-term initiative of the FDA to facilitate international standardization in drug testing and drug approval ("harmonization"). Various FDA Centers coordinate regular conferences with colleagues in Europe, Japan, Canada, and Australia. The benefits of harmonization of drug and biologic DMARD testing in pediatric rheumatic diseases include a decrease of unnecessary exposure to placebo or potentially unsafe new medications. Harmonization efforts are especially evident in the context of pediatric drug trials. This is achieved by international agreement between the various regulatory agencies on the design and performance of only a single blinded controlled pediatric trial, rather than several studies.

\section{Research network focused on promoting access to new medications for pediatric rheumatic disease therapy}

Founded in 1973, the PRCSG is a research network of nearly 90 academic clinical pediatric rheumatology centers. At present, there are over 180 pediatric rheumatology investigators in North America and Puerto Rico who are members of the PRCSG. The mission of the PRCSG (http://www.prcsg.org) is to foster, facilitate, and conduct high quality clinical research in the field of pediatric rheumatology. The PRCSG Advisory Council provides oversight of the network's activities. Its members are established clinical investigators, a junior clinical investigator, and representatives of foundations, organizations, and government agencies pertinent to the mission of the network, such as the National Institutes of Health and FDA.

The impact of the PRCSG extends beyond North America. The PRCSG leadership was involved in the training of the leadership of the Paediatric Rheumatology International Trials Organisation (PRINTO; http://printo.it) [10], a research network that now includes centers in Europe, Latin America, Asia and Africa, and whose mission is aligned with that of the PRCSG. These two networks have 
been active collaborators for over 20 years, which ultimately supports licensure of new medicines in many countries throughout the world.

Studies in pediatric rheumatic diseases often require complex response measures; necessitate adjustment of background medications; and rules for early discontinuation of subjects for added safety. To ensure that study protocols are closely followed by the investigative sites, the PRCSG and PRINTO Coordinating Centers have developed standardized operating procedures, custom software, electronic data capture systems and databases, as well as data security and back-up systems. This robust infrastructure allows the Coordinating Centers to provide real-time feed-back to investigative sites throughout the world and across all time zones. Although focused on pharmaceutical supported trials, the PRCSG Coordinating Center also supports investigator-initiated studies [11, 12].

\section{The scientific collaboration treaty between the U. S. and Union of Soviet Socialist Republics supported early clinical trials in JIA}

During the Cold War era, and as part of a Scientific Collaboration Treaty between the State Departments of the U.S. and the Union of Soviet Socialist Republics (USSR), the PRCSG conducted trials of popular traditional Disease Modifying Anti-Rheumatic Drugs (DMARDs) with pediatric rheumatologists in the U.S. and the USSR. The motivation behind the Scientific Collaboration Treaty was that the fostering of scientific collaboration between the two countries was hoped to promote collaborations in other realms. Dr. Earl Brewer, the founder and first chairman of the PRCSG, considered the Scientific Collaboration Treaty a unique opportunity to obtain federal funding for clinical trials in JIA.

Facilitated by the Scientific Collaboration Treaty, three large, pivotal Phase III randomized, double-blind, placebo-controlled trials of DMARDs were successfully performed through the collaborative efforts of pediatric rheumatologists in the U.S. and the USSR. The first study compared the efficacy of D-penicillamine and hydroxychloroquine to placebo in polyarticular JIA [13]. Despite promising results in open-label clinical studies, the results of the controlled study proved that neither D-penicillamine nor hydroxychloroquine were superior to placebo in JIA. Thus, this PRCSG study spared other children with JIA treatment with these ineffective medications. A second clinical trial compared the efficacy and safety of oral gold to that of placebo in polyarticular JIA. Despite earlier positive clinical trials of oral gold in RA, this PRCSG study supported that oral gold was only marginally superior to placebo and had considerable toxicity when used in JIA [14]. Taken together, this PRCSG trial again prevented JIA patients from treatment with minimally effective yet potentially toxic oral gold therapy.
The third trial was of methotrexate versus placebo in active polyarticular JIA [15]. Only oral methotrexate at $10 \mathrm{mg} /$ $\mathrm{m}^{2}$ body surface area (BSA) once per week, but not the lower weekly dose of $5 \mathrm{mg} / \mathrm{m}^{2}$ BSA, proved to be superior to placebo in JIA. The results of this study were specifically used for the subsequent labeled indication of methotrexate in reducing signs and symptoms of polyarticular JIA.

Other trials performed by the PRCSG were of various nonsteroidal anti-inflammatory drugs (NSAIDs), which were formerly the cornerstone of JIA treatments [1623]. These studies led to FDA approval of five NSAIDs for JIA (Table 1).

\section{Clinical trials of biological DMARDs result in markedly improved prognosis of JIA with polyarticular joint involvement}

The first biologic DMARD studied in JIA was etanercept, a fusion protein targeting tumor necrosis factor alpha (TNF $\alpha)$ [24]. The efficacy of etanercept in JIA was tested and established using the then novel randomized

Table 1 Medications studied by the PRCSG Pediatric Rheumatology Collaborative Study Group for Juvenile Idiopathic Arthritis and other pediatric rheumatic diseases by route(s) of administration $^{\text {a }}$

\begin{tabular}{|c|c|c|}
\hline $\begin{array}{l}\text { Medications studied } \\
\text { but without approval/ } \\
\text { licensure by regulatory } \\
\text { agencies }\end{array}$ & $\begin{array}{l}\text { Medications studied } \\
\text { with approval/licensure } \\
\text { by regulatory agencies }\end{array}$ & $\begin{array}{l}\text { Studies in } \\
\text { Progress }\end{array}$ \\
\hline Oral & Oral & Oral \\
\hline D-penicillamine & Celecoxib & Baricitinib \\
\hline Fenoprofen & Ibuprofen & Tofacitinib \\
\hline Gold & Naproxen & Subcutaneous \\
\hline Hydroxychloroquine & Rofecoxib $^{b}$ & Certolizumab pegol \\
\hline Ketoprofen & Tolmetin & Sarilumab \\
\hline Meclofenamate & $\begin{array}{l}\text { Oral, subcutaneous } \\
\text { or intramuscular }\end{array}$ & Secukinumab \\
\hline Oxaprozin & Methotrexate & Tocilizumab \\
\hline Pirprofen & Subcutaneous & Intravenous \\
\hline Proquazone & Adalimumab & Belimumab $^{g}$ \\
\hline Subcutaneous & Canakinumab ${ }^{c}$ & Golimumab \\
\hline Anakinra & Etanercept & Rituximab $^{\mathrm{h}}$ \\
\hline Intravenous & Golimumab ${ }^{d}$ & \\
\hline $\begin{array}{l}\text { Intravenous } \\
\text { immunoglobulin }\end{array}$ & $\begin{array}{l}\text { Subcutaneous and/or } \\
\text { intravenous }\end{array}$ & \\
\hline Infliximab & Abatacept $^{\mathrm{e}}$ & \\
\hline Rilonacept & Tocilizumab $^{f}$ & \\
\hline
\end{tabular}

Biologic medications are printed in Italics

${ }^{b}$ Approval withdrawn by the U.S. Food and Drug Administration due to safety concerns in adults with rheumatoid arthritis

cOnly for systemic juvenile idiopathic arthritis (JIA)

${ }^{d}$ Approved by European Medicines Agency only, but not by the U.S. Food and Drug Administration

${ }^{\mathrm{e}}$ Both the intravenous and the subcutaneous form is approved for polyarticular JIA

${ }^{\text {T}}$ The intravenous forms are approved for systemic JIA and polyarticular JIA ${ }^{g}$ For systemic lupus erythematosus

${ }^{h}$ For antineutrophil cytoplasmic autoantibody (ANCA) associated vasculitis 
withdrawal design (RWD). This RWD study $(n=69)$ was fully enrolled within 3 months from sites in North America because many children with JIA had failed all available medications. When the first JIA patient was dosed with etanercept, only about 300 adult patients with RA had been treated with this drug. Etanercept remains the first and presently only biologic DMARD that achieved regulatory approval by the FDA using the "fast track" approach. Eventually, world-wide approval of etanercept for polyarticular JIA was achieved based on the results of this PRCSG trial. However, given its small sample size and short duration of follow-up, the FDA required the Sponsor to establish a large post-marketing Phase IV JIA registry to document the continued effectiveness, benefits on quality of life, and longer-term safety of etanercept in routine clinical use, including usage in younger children [25]. These studies resulted in important additions to the label for etanercept pertaining to medication safety events, and broadened the approval to children as young as 2 years. Subsequent to the etanercept study, there have been a series of clinical trials managed by the PRCSG and PRINTO, which resulted in FDA approval of a total of six biologic DMARDs for polyarticular JIA [24, 26-30].

In the last decade, PRCSG investigators also participated in clinical trials in systemic JIA (SJIA) [31-33]. The trials of canakinumab, an interleukin (IL)- $1 \beta$ monoclonal antibody, and the anti-IL- 6 monoclonal antibody, tocilizumab, in SJIA led to the regulatory approval of both biologic DMARDs in North America and Europe [32,33]. A list of all medications studied by the PRCSG, including those that are now licensed for JIA, is provided in Table 1 .

With the advent of designer drugs that target pathways only relevant to some rare JIA subsets, the corresponding clinical trials in children constitute an even larger challenge. Examples are drugs that inhibit the IL-17 or IL-12/ 23 pathways which are expected to only benefit children with juvenile psoriatic arthritis and /or enthesitis-related JIA. The PRCSG has also been involved in the planning and conduct of the pediatric clinical trials of the anti-B lymphocyte stimulator monoclonal antibody, belimumab, in systemic lupus erythematosus (SLE), and the anti-CD20 monoclonal antibody, rituximab, in anti-neutrophil cytoplasmic antibody associated vasculitis.

\section{Global commitments and access to care}

Since 2000, JIA medication trials generally involved pediatric rheumatology centers located all over the world, including in developing countries where access to affordable biologic DMARDs remains limited. The PRCSG and PRINTO have adopted the guiding principle that, irrespective of regulatory approval in the child's country, study participants must be provided long-term access to the study agent, as long as it is deemed medically beneficial to the child. The mechanism by which medication is provided to former study participants varies country by country. Despite the added cost, to date, all pharmaceutical companies have agreed to this request of the PRCSG and PRINTO.

\section{Development of outcome and response measures for pediatric rheumatic diseases}

The PRCSG published the first guidance papers concerning medication studies in JIA [34, 35]. Many of the recommendations from 1982 continue to be relevant: well validated outcome measures are deemed a sinequa-non for the successful conduct of clinical trials. Members of the PRCSG Advisory Council have held the view that it is unethical and scientifically unacceptable to proceed with large scale trials, if validated response criteria [36] are unavailable. Often in collaboration with other pediatric rheumatic disease networks, the PRCSG has been an active participant in the development and validation of outcomes measures (see Table 2 for listing of developed measures). The most frequently used outcome measures and response criteria include those for

Table 2 Clinical trial outcome measures developed by the Pediatric Rheumatology Collaborative Study Group Leadership in collaboration with other pediatric rheumatology networks

\begin{tabular}{|c|c|c|}
\hline $\begin{array}{l}\text { PEDIATRIC RHEUMATIC } \\
\text { DISEASE }\end{array}$ & Outcome measure & Reference \\
\hline \multirow{5}{*}{$\begin{array}{l}\text { Juvenile Idiopathic } \\
\text { Arthritis }\end{array}$} & Core set of Outcome Measures $^{a}$ & {$[35]$} \\
\hline & $\begin{array}{l}\text { Preliminary Definition of } \\
\text { Improvement }{ }^{\mathrm{a}}\end{array}$ & {$[36]$} \\
\hline & Preliminary Flare Criteria ${ }^{a}$ & {$[37]$} \\
\hline & $\begin{array}{l}\text { Provisional criteria for inactive } \\
\text { disease \& clinical remission }{ }^{\mathrm{a}}\end{array}$ & {$[38]$} \\
\hline & Macrophage Activation Syndrome ${ }^{a}$ & [39] \\
\hline \multirow{6}{*}{$\begin{array}{l}\text { Systemic Lupus } \\
\text { Erythematosus }\end{array}$} & Disease activity & [40] \\
\hline & Disease damage & [41] \\
\hline & Core Set of Outcome Measures $^{\mathrm{a}}$ & {$[42]$} \\
\hline & Provisional Improvement Criteria ${ }^{\mathrm{b}}$ & [43] \\
\hline & Preliminary Flare Criteriab & [44] \\
\hline & $\begin{array}{l}\text { Preliminary Inactive Disease } \\
\text { Criteriab }^{\text {b }}\end{array}$ & [45] \\
\hline \multirow[t]{3}{*}{$\begin{array}{l}\text { Juvenile } \\
\text { Dermatomyositis }\end{array}$} & $\begin{array}{l}\text { Childhood Myositis Activity } \\
\text { Assessment Scale }\end{array}$ & [46] \\
\hline & $\begin{array}{l}\text { Core set measures of disease } \\
\text { activity and damage }^{a}\end{array}$ & [42] \\
\hline & $\begin{array}{l}\text { Provisional Criteria for Response } \\
\text { to Therapy }{ }^{\mathrm{a}}\end{array}$ & [47] \\
\hline
\end{tabular}

${ }^{a}$ Developed in collaboration with Pediatric Rheumatology International Trials Organization (PRINTO)

${ }^{b}$ Developed in collaboration with PRINTO and Childhood Arthritis and Rheumatology Research Alliance (CARRA)

'Developed in collaboration with Juvenile Dermatomyositis Disease Activity Collaborative Study Group (predecessor to International Myositis Assessment and Clinical Studies Group) 
JIA [37-41]. The PRCSG leadership has also been involved in the delineation of core outcome measures and response criteria for SLE [42-47] and juvenile dermatomyositis $[44,48,49]$.

\section{Novel study designs to maximize study efficiency}

Pediatric rheumatic diseases are uncommon, and almost all affect fewer than 200,000 individuals in the US, which is compared to 1.3 million adult patients diagnosed with RA [50]. Pediatric rheumatic diseases are considered orphan or rare diseases as defined by the Orphan Drug Act [51]. Although JIA is the most common pediatric rheumatic disease, its prevalence is only 44.7 (95\% CI 39.1-50.2) per 100,000 persons in the U.S. [52]. Thus, children with pediatric rheumatic diseases are a precious resource, and adequately powered clinical trials require an international enrollment strategy. Considering the burden of active pediatric rheumatic diseases, it is also critical for controlled studies to minimize placebo exposure while maximizing the collection of safety data. Therefore, the PRCSG has developed and used a randomized withdrawal design (RWD) for many of the controlled trials [24, 27, 29]. Beyond pediatric rheumatology, the RWD is now also used for the studies in, among others, gastrointestinal and neuropsychiatric diseases [53, 54]. As shown in Fig. 1, RWD trials provide active study drug to all study participants during the open label lead-in period (Part 1). Only subjects who have experienced a protocol-defined improvement in disease signs and symptoms will be randomized to enter the blinded placebo-controlled of a RWD trial (Part 2), while non-responders are either discontinued from the study at the end of Part 1 or allowed enter an open-label extension phase with access to active study drug (Part 3). All subjects who complete the blinded Part 2 can continue to receive active drug during Part 3. Study participants remain in the blinded treatment phase until the last visit in Part 2 or until he/she experiences a 'disease flare, i.e., a protocol-defined disease worsening, whichever comes first. Therefore, study participants remain in Part 2 only as long as they continue to demonstrate at least a similar level of disease control as at the beginning of Part 2, which is better than at the beginning of Part 1 . The primary endpoint of a RWD trial is either the proportion of patients with 'disease flare' compared to the time of randomization, or the time to 'disease flare' in Part 2. Advantages of the RWD include a high degree of efficiency in assessing drug efficacy, requiring fewer patients to be enrolled in the trial; an individualized duration of exposure to placebo with an option to restart open-label active drug upon experiencing a 'disease flare'. The disadvantages of the RWD trial are as follows: (1) there may exist a selection bias because only subjects who responded in the open lead-in phase are randomized into the double-blind phase, while children who failed to respond Part 1, and hence may have a lesser probability of favorable response to drug, are excluded from Part 2; (2) the primary outcome is not a direct comparison of response rates between treatment arms, but rather an indirect one (i.e., 'disease flare'); (3) given that patients receiving placebo in the blinded portion are more likely to have a 'disease flare' and exit Part 2 early, there is often only a small blinded placebo safety exposure dataset. Despite these limitations, the RWD has functioned well in numerous JIA trials [24, 27-29, 33].

Use of traditional double-blind placebo-controlled parallel design may be considered in pediatric rheumatic

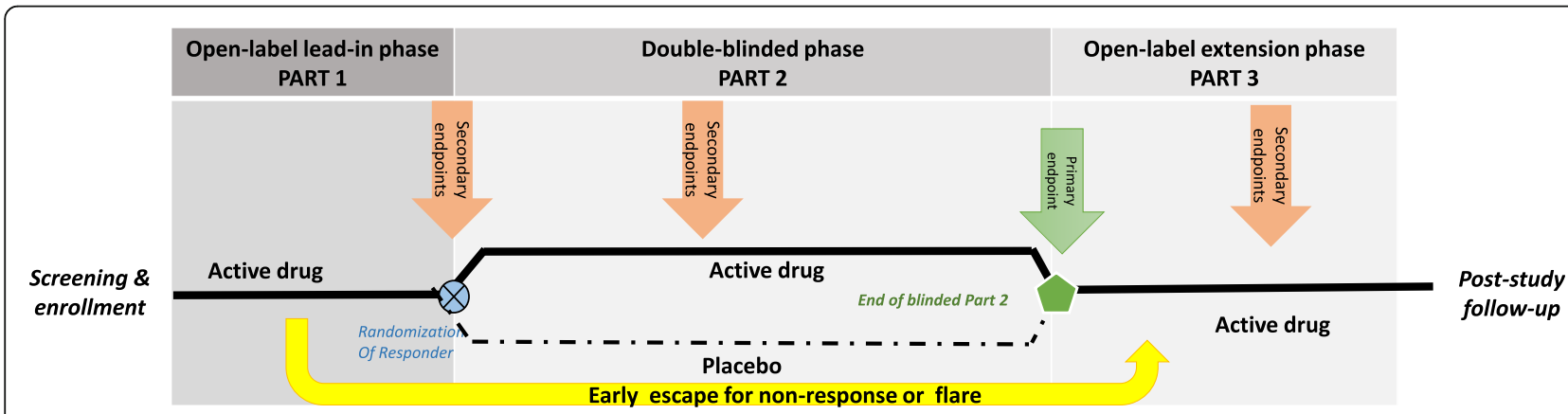

Fig. 1 Basic design of Randomized Withdrawal Design. A randomized withdrawal design (RWD) study consists of three parts. During Part 1 and Part 3 all study participants receive open-label active study drug. Participants who show a clinically meaningful response to study drug by the end of Part 1 are randomized to the double-blinded placebo-controlled Part 2. Participants move from Part 2 to Part 3 if there is a flare event during Part 2 or upon completion of all Part 2 visits, whichever comes first. Patients for whom study drug may be beneficial, but who did not meet criteria for a meaningful improvement during Part 1, may be allowed to enter Part 3. The primary endpoint of a RWD trial is 'the time to disease flare or the occurrence of a flare event during Part 2. The participant's disease status at the end of Part 1 is used as the baseline to assess whether disease worsening (flare) has occurred during Part 2. Secondary RWD study endpoints can be measured throughout the duration of the entire RWD trial (Part 1 through 3) and include achievement of inactive disease, success in tapering certain background medications and change in patient reported outcomes 
diseases if (1) the new drug is fast-acting, hence the duration of placebo exposure is expected to be very short; (2) the new drug is not dosed continuously or has a very prolonged effect and therefore awaiting disease flare after therapy withdrawal would be impractical; or (3), there are safety concerns with sudden drug discontinuation of study drug in Part 2 of the RWD trials [32]. Whenever parallel designs are used, the PRCSG strongly advocates that there are liberal, early escape rules and an open label extension study. Such aspects of clinical development program ensure that patients with poor disease control have access to active drug early and over extended time periods.

In addition to placebo-controlled studies, the PRCSG uses open-label designs of studies for drug labeling purposes, provided the mechanism of action of a given drug is known to consistently result in improvement of a rheumatic disease in both children and adults, considering earlier controlled studies [55]. Open-label studies of "me-too" medications assume that the risk-benefit profile of a given drug is comparable to that of other drugs with a similar mechanism of action. The primary objective of such open-label studies in JIA is the identification of dosing regimens that result in drug exposures that have been found efficacious in RA. Regulatory agencies accepted an open-label study of certolizumab pegol in JIA (NCT01550003). This monoclonal antibody blocks TNF $\alpha$-mediated inflammation in a similar manner to infliximab, adalimumab, and golimumab, i.e. biological
DMARDs that have been found to be efficacious in controlled studies in RA and JIA. Other examples in JIA include intravenous golimumab (NCT02277444), and the study of subcutaneous abatacept.

Modification of the above-mentioned controlled and uncontrolled study designs include elements considered in adaptive trial designs. Examples are the reduction of sample size following planned interim analyses, the tapering of corticosteroids during the RWD trial of canakinumab in SJIA [33]; and protocolized discontinuation of methotrexate, NSAIDs, and even study drug, during the long-term phase of tocilizumab trial in SJIA [32].

Taken together, the PRCSG advocates study designs for new drugs that minimize placebo and background medication exposures. Nonetheless, any study by the PRCSG maintains sufficient scientific rigor needed for subsequent drug approval by regulatory agencies. Another prerequisite of PRCSG trials is that large-scale Phase III studies only proceed after the delineation of the dosing regimen that provides comparable drug exposure to those known to be efficacious in the related adult rheumatic disease. If the pathogenesis of the pediatric disease is distinct from the approved adult disease (e.g., RA and SJIA), dose-finding Phase II studies must be performed prior to the initiation of the Phase III trials used for achieving marketing approval [32]. Phase II dose finding studies were performed for both canakinumab and tocilizumab in SJIA [56, 57].

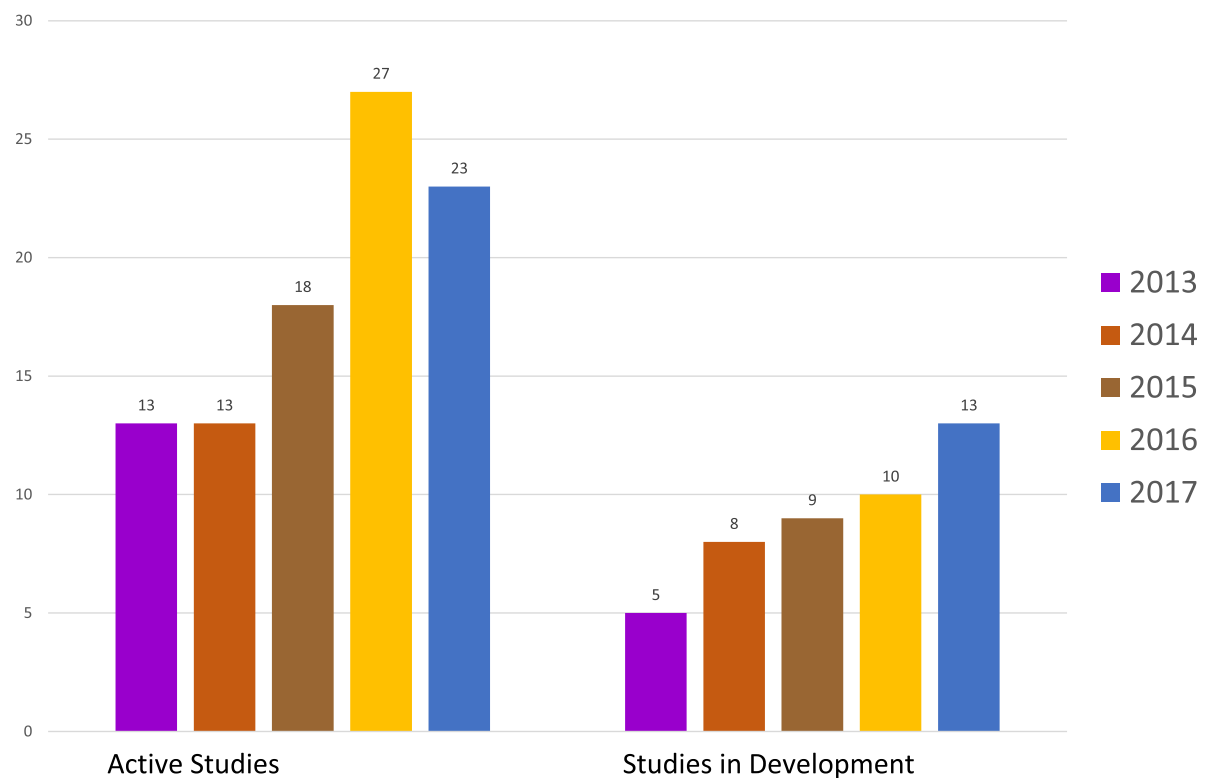

Fig. 2 The PRCSG is a productive collaborative research network with focus on medication studies in pediatric rheumatic diseases. The PRCSG network has been continuously active with the number of studies active or in development markedly increasing since the passage of FDA Safety and Innovation Act (FDASIA) in 2012 


\section{Other activities of the PRCSG}

Besides optimizing study designs, the PRCSG is actively engaged in the training of pediatric rheumatology investigators. This includes formal training and certification of quantitated reporting of the joint evaluation in children (Joint Assessor Certification) [58] and the training in the completion of other outcome measures for clinical trials. The PRCSG also provides special mentoring and training to investigators or pediatric rheumatology sites new to drug trials. In recognition of the changing landscape of medical care, the PRCSG now actively invites membership applications from nurse practitioners, physician assistants, and pediatric rheumatology trainees involved in the care of children with rheumatic diseases.

It is the intent of the PRCSG to facilitate translational research studies in pediatric rheumatic diseases. This has proven to be difficult as pharmaceutical firms are determined to minimize trial costs and logistic demands. Generally, the collection of biological samples during studies paid for by biopharmaceutical companies focus on the demands of regulatory agencies and the pharmaceutical sponsor in-house research portfolio. To make matters worse, there were no internationally-accepted standard protocols for the collection, shipping, processing, and storage of pediatric rheumatology biological samples until recently. This short-coming has been addressed by the international consortium UCAN (Understanding Childhood Arthritis Network) [36, 59]. The PRCSG interacts with UCAN in supporting translational research by pediatric rheumatology investigators that make use of samples and data from drug trials. A recent example is the gene profiling study in SIIA patients treated with canakinumab [60].

\section{Conclusions}

Since the 1970's, the PRCSG has contributed to the methodology of performing trials in pediatric rheumatic diseases. Closely collaborating with PRINTO and industry sponsors, 25 drugs and biologic agents have been studied by the network, resulting in 13 drug and biologic therapies achieving labeling for JIA by the FDA and/or EMA as of 2018. These drugs have dramatically improved the outcomes of children with polyarticular and systemic forms of JIA, leading to improved growth, quality of life, and possibly reduced radiographic joint erosions [61-65]. Upcoming clinical studies undertaken by the PRCSG (see Fig. 2) are expected to yield the licensure of additional drugs for children with various subsets of JIA and other pediatric rheumatic diseases.

\section{Abbreviations}

BPCA: Best Pharmaceuticals for Children Act; BSA: Body surface area; CBER: Center for Biologics Evaluation and Research; CDER: Center for Drug Evaluation and Research; DMARDs: Disease Modifying Anti-Rheumatic Drugs; EMA: European Medicines Agency; FD\&C Act: Food, Drug, and Cosmetic Act; FDA: Food and Drug Administration; FDASIA: FDA Safety and Innovation Act; IL: Interleukin; iPSP: Initial Pediatric Study Plan; JA: Juvenile idiopathic arthritis; PDCO: Paediatric Committee; PIP: Paediatric Investigational Plan; PRCSG: Pediatric Rheumatology Collaborative Study Group; PREA: Pediatric Research Equity Act; PRINTO: Paediatric Rheumatology International Trial Organisation; RA: Rheumatoid arthritis; RWD: Randomized withdrawal design; U.S.: United States; UCAN: Understanding Childhood Arthritis Network; USSR: Union of Soviet Socialist Republics

\section{Acknowledgements}

We thank Drs. Robert Colbert and James McNamara for critical review of the manuscript. We would like to thank Drs. Suzette Peng and Sarah Yim for their service on the PRCSG Advisory Council.

Robert Colbert ColbertR@mail.nih.gov

James McNamara jmcnamara@niaid.nih.gov

Suzette Peng Suzette.Peng@fda.hhs.gov

Sarah Yim sarah.yim@fda.hhs.gov

\section{Funding}

This review was supported in part by the Intramural Research Program of the National Institute of Environmental Health Sciences (project ES101081, Lisa Rider) and National Institute of Allergy Immunology and Infectious Diseases (Ellen Goldmuntz), National Institutes of Health, Bethesda, MD. Salary support was provided for these two authors by NIH. Supervisors of Drs. Rider and Goldmuntz reviewed the manuscript and approved content and authorship of Drs. Rider and Goldmuntz.

Availability of data and materials

Data sharing not applicable to this article as no datasets were generated or analyzed during the current study.

\section{Authors' contributions}

First draft: HB. Critical feed-back, revisions and edits: HB; LGR; DJK; DC; RS; EG; KBO; EHG; DJL. Substantial contributions to conception and design, or acquisition of data, or analysis and interpretation of data. HB; LGR; DJK; DC; RS; EG; KBO; EHG; DJL. Final approval of submitted version: HB; LGR; DJK; DC; RS; EG; $\mathrm{KBO}$; EHG; DJL. Agreed to be accountable for all aspects of the work in ensuring that questions related to the accuracy or integrity of any part of the work are appropriately investigated and resolved. HB; LGR; DJK; DC; RS; EG; $\mathrm{KBO}$; EHG; DJL.

Ethics approval and consent to participate

Not applicable. This research review does not report on human participants, human data or human or animal experiments.

Consent for publication

Not applicable.

\section{Competing interests}

Dr. Lovell is Chairman of the PRCSG, Dr. Brunner is the Scientific Director of the PRCSG. All other named authors are members of the PRCSG Advisory Council. Drs. Yim and Peng are also members of the Advisory Council and reviewed the manuscript but deemed their contributions to the manuscript not significant enough to be included as named authors.

\section{Publisher's Note}

Springer Nature remains neutral with regard to jurisdictional claims in published maps and institutional affiliations.

\section{Author details}

${ }^{1}$ Division of Rheumatology, Cincinnati Children's Hospital Medical Center \& Cincinnati Children's Research Foundation, MLC 4010, Cincinnati, OH 45229, USA. 'Environmental Autoimmunity Group, Clinical Research Branch, National Institute of Environmental Health Sciences, National Institutes of Health, Bethesda, MD, USA. ${ }^{3}$ Randall Children's Hospital at Legacy Emanuel, Portland, OR, USA. ${ }^{4}$ University of Wisconsin School of Medicine and Public Health, Madison, WI, USA. ${ }^{5}$ The Hospital for Sick Children, University of Toronto, Toronto, Canada. ${ }^{6}$ Division of Allergy, Immunology, and Transplantation, Rheumatologic Autoimmune Diseases Section, National Institutes of Health, Bethesda, MD, USA. ${ }^{7}$ Hospital for Special Surgery, Weill Cornell Medicine, New York, NY, USA. 


\section{Received: 6 May 2018 Accepted: 20 June 2018}

\section{Published online: 11 July 2018}

\section{References}

1. Neville KA, Frattarelli DA, Galinkin JL, et al. Off-label use of drugs in children. Pediatrics. 2014;133(3):563-7.

2. Rose AC, van't Hoff W, Beresford MW, Tansey SP. NIHR medicines for children research network: improving children's health through clinical research. Expert Rev Clin Pharmacol. 2013;6(5):581-7.

3. Best pharmaceuticals for children act of 2007. Food and Drug Administration Amendments Act (FDAAA), Title V Vol Public Law No. 110-85.

4. Pediatric Research Equity Act. Pub L; 2003. p. No. 108-55.

5. Field MJ, Boat TF, Institute of Medicine (U.S.), National Research Council (U.S. ). Safe and effective medicines for children : pediatric studies conducted under the best Pharmaceuticals for Children act and the pediatric research equity act. Washington, D.C.: The National Academies Press; 2012.

6. U.S. Food and Drug Administration. Guidance for Industry: Clinical development programs for drugs, devices, and biological products for the treatment of rheumatoid arthritis (RA). 1999. https://www.fda.gov/ downloads/Drugs/Guidances/ucm071579.pdf.

7. Califf R. Best Pharmaceuticals for Children act and Pediatric Research Equity act - July 2016 report to congress. 2016. https:/www.fda.gov/downloads/ ScienceResearch/SpecialTopics/PediatricTherapeuticsResearch/UCM509815.pdf.

8. Turner MA, Attar S, de Wildt SN, Vassal G, Mangiarini L, Giaquinto C. Roles of clinical research networks in pediatric drug development. Clin Ther. 2017; 39(10):1939-48.

9. U.S. Food and Drug Administration. Guidance for industry: pediatric study plans - content of and process for submitting initial pediatric study plans and amended initial pediatric study plans 2016. https://www.fda.gov/ downloads/drugs/guidancecomplianceregulatoryinformation/guidances/ ucm360507.pdf.

10. Ruperto N, Martini A. International research networks in pediatric rheumatology: the PRINTO perspective. Curr Opin Rheumatol. 2004;16(5): $566-70$

11. Wallace CA, Giannini EH, Spalding SJ, et al. Trial of early aggressive therapy in polyarticular juvenile idiopathic arthritis. Arthritis Rheum. 2012;64(6):2012-21.

12. Hashkes PJ, Spalding SJ, Giannini EH, et al. Rilonacept for colchicine-resistant or -intolerant familial Mediterranean fever: a randomized trial. Ann Intern Med. 2012;157(8):533-41.

13. Brewer EJ, Giannini EH, Kuzmina N, Alekseev L. Penicillamine and hydroxychloroquine in the treatment of severe juvenile rheumatoid arthritis. N Engl J Med. 1986;314(20):1269-76.

14. Brewer EJ Jr, Giannini EH, Barkley E. Gold therapy in the management of juvenile rheumatoid arthritis. Arthritis Rheum. 1980;23(4):404-11.

15. Giannini E, Brewer E, Kuzmina N, et al. Methotrexate in resistant juvenile rheumatoid arthritis: results of the USA-USSR double-blind, placebocontrolled trial. N Engl J Med. 1992;326(16):1043-9.

16. Bass J, Giannini E, Brewer E, et al. Pirprofen (Rengasil) in the treatment of juvenile rheumatoid arthritis. A segment I study. J Rheumatol. 1982; 9(1):140-3.

17. Brewer E, Giannini E, Baum J, et al. Aspirin and fenoprofen (Nalfon) in the treatment of juvenile rheumatoid arthritis results of the double blind-trial. A segment II study. J Rheumatol. 1982;9(1):123-8.

18. Brewer E, Giannini E, Baum J, et al. Sodium meclofenamate (Meclomen) in the treatment of juvenile rheumatoid arthritis. A segment I study. J Rheumatol. 1981;9(1):129-34.

19. Brewer E, Giannini E, Baum J, et al. Proquazone (Biarsan) in the treatment of juvenile rheumatoid arthritis. A segment I study. J Rheumatol. 1982;9(1):135-9.

20. Foeldvari I, Szer IS, Zemel LS, et al. A prospective study comparing celecoxib with naproxen in children with juvenile rheumatoid arthritis. J Rheumatol. 2009;36(1):174-82

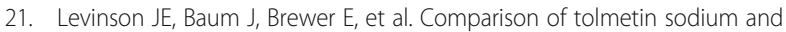
aspirin in the treatment of juvenile rheumatoid arthritis. J Pediatr. 1977; 91(5):799-804

22. Reiff A, Lovell DJ, Van Adelsberg J, et al. Evaluation of the comparative efficacy and tolerability of rofecoxib and naproxen in children and adolescents with juvenile rheumatoid arthritis: a 12-week randomized controlled clinical trial with a 52-week open-label extension. J Rheumatol. 2006;33(5):985-95
23. Sobel RE, Lovell DJ, Brunner HI, et al. Safety of celecoxib and nonselective nonsteroidal anti-inflammatory drugs in juvenile idiopathic arthritis: results of the phase 4 registry. Pediatr Rheumatol. 2014;12(1):29.

24. Lovell DJ, Giannini EH, Reiff A, et al. Etanercept in children with polyarticular juvenile rheumatoid arthritis. Pediatric rheumatology collaborative study group. N Engl J Med. 2000;342(11):763-9.

25. Giannini EH, llowite NT, Lovell DJ, et al. Long-term safety and effectiveness of etanercept in children with selected categories of juvenile idiopathic arthritis. Arthritis Rheum. 2009;60(9):2794-804.

26. Ruperto N, Lovell DJ, Cuttica R, et al. A randomized, placebo-controlled trial of infliximab plus methotrexate for the treatment of polyarticular-course juvenile rheumatoid arthritis. Arthritis Rheum. 2007;56(9):3096-106.

27. Lovell DJ, Ruperto N, Goodman S, et al. Adalimumab with or without methotrexate in juvenile rheumatoid arthritis. N Engl J Med. 2008;359(8): 810-20.

28. Ruperto N, Lovell DJ, Quartier P, et al. Abatacept in children with juvenile idiopathic arthritis: a randomised, double-blind, placebo-controlled withdrawal trial. Lancet. 2008;372(9636):383-91.

29. Brunner HI, Ruperto N, Zuber Z, et al. Efficacy and safety of tocilizumab in patients with polyarticular-course juvenile idiopathic arthritis: results from a phase 3, randomised, double-blind withdrawal trial. Ann Rheum Dis. 2015; 74(6):1110-7.

30. Brunner HI, Ruperto N, Tzaribachev N, Horneff G, Chasnyk VG, Panaviene V, Abud-Mendoza C, Reiff A, Alexeeva E, Rubio-Pérez N, Keltsev V. Subcutaneous golimumab for children with active polyarticular-course juvenile idiopathic arthritis: results of a multicentre, double-blind, randomised-withdrawal trial. Ann Rheum Dis. 2017:annrheumdis-2016.

31. Lovell DJ, Giannini EH, Reiff AO, et al. Long-term safety and efficacy of rilonacept in patients with systemic juvenile idiopathic arthritis. Arthritis Rheum. 2013:65(9):2486-96.

32. De Benedetti F, Brunner HI, Ruperto N, et al. Randomized trial of tocilizumab in systemic juvenile idiopathic arthritis. N Engl J Med. 2012; 367(25):2385-95.

33. Ruperto N, Brunner HI, Quartier P, et al. Two randomized trials of canakinumab in systemic juvenile idiopathic arthritis. N Engl J Med. 2012; 367(25):2396-406

34. Giannini EH, Brewer EJ Jr. Standard methodology for segment I, II, and III pediatric rheumatology collaborative study group studies. II. Analysis and presentation of data. J Rheumatol. 1982;9(1):114-22.

35. Brewer EJ Jr, Giannini EH. Standard methodology for segment I, II, and III pediatric rheumatology collaborative study group studies. I. Design. J Rheumatol. 1982;9(1):109-13.

36. Singh JA, Solomon DH, Dougados $M$, et al. Development of classification and response criteria for rheumatic diseases. Arthritis Rheum. 2006;55(3): 348-52.

37. Ruperto N, Giannini EH. Redundancy of conventional articular response variables used in juvenile chronic arthritis clinical trials. Ann Rheum Dis. 1996;55(1):73-5.

38. Giannini EH, Ruperto N, Ravelli A, Lovell DJ, Felson DT, Martini A. Preliminary definition of improvement in juvenile arthritis. Arthritis Rheum. 1997:40(7):1202-9.

39. Brunner HI, Lovell DJ, Finck BK, Giannini EH. Preliminary definition of disease flare in juvenile rheumatoid arthritis. J Rheumatol. 2002;29(5):1058-64.

40. Wallace CA, Giannini EH, Spalding SJ, et al. Clinically inactive disease in a cohort of children with new-onset polyarticular juvenile idiopathic arthritis treated with early aggressive therapy: time to achievement, total duration, and predictors. J Rheumatol. 2014;41(6):1163-70.

41. Ravelli A, Minoia F, Davì S, et al. 2016 classification criteria for macrophage activation syndrome complicating systemic juvenile idiopathic arthritis: a European league against rheumatism/American College of Rheumatology/Paediatric rheumatology international trials organisation collaborative initiative. Arthritis Rheumatol. 2016;68(3): 566-76.

42. Brunner HI, Feldman BM, Bombardier C, Silverman ED. Sensitivity of the systemic lupus erythematosus disease activity index, British isles lupus assessment group index, and systemic lupus activity measure in the evaluation of clinical change in childhood-onset systemic lupus erythematosus. Arthritis Rheum. 1999;42(7):1354-60.

43. Brunner HI, Silverman ED, To T, Bombardier C, Feldman BM. Risk factors for damage in childhood-onset systemic lupus erythematosus: cumulative disease activity and medication use predict disease damage. Arthritis Rheum. 2002;46(2):436-44 
44. Ruperto N, Ravelli A, Murray KJ, et al. Preliminary core sets of measures for disease activity and damage assessment in juvenile systemic lupus erythematosus and juvenile dermatomyositis. Rheumatology (Oxford). 2003; 42(12):1452-9.

45. Ruperto N, Ravelli A, Cuttica R, et al. The pediatric rheumatology international trials organization criteria for the evaluation of response to therapy in juvenile systemic lupus erythematosus: prospective validation of the disease activity core set. Arthritis Rheum. 2005;52(9): 2854-64.

46. Brunner $\mathrm{HI}$, Mina R, Pilkington $\mathrm{C}$, et al. Preliminary criteria for global flares in childhood-onset systemic lupus erythematosus. Arthritis Care Res (Hoboken). 2011;63(9):1213-23.

47. Mina R, Klein-Gitelman MS, Ravelli A, et al. Inactive disease and remission in childhood-onset systemic lupus erythematosus. Arthritis Care Res (Hoboken). 2012;64(5):683-93.

48. Lovell DJ, Lindsley CB, Rennebohm RM, et al. Development of validated disease activity and damage indices for the juvenile idiopathic inflammatory myopathies. II. The childhood myositis assessment scale (CMAS): a quantitative tool for the evaluation of muscle function. The juvenile dermatomyositis disease activity collaborative study group. Arthritis Rheum. 1999:42(10):2213-9.

49. Ruperto N, Pistorio A, Ravelli A, et al. The Paediatric rheumatology international trials organisation provisional criteria for the evaluation of response to therapy in juvenile dermatomyositis. Arthritis Care Res (Hoboken). 2010;62(11):1533-41.

50. Helmick CG, Felson DT, Lawrence RC, et al. Estimates of the prevalence of arthritis and other rheumatic conditions in the United States: part I. Arthritis Rheumatol. 2008;58(1):15-25.

51. Boat TF, Field MJ. Rare diseases and orphan products: accelerating research and development. Washington, DC: National Academies Press; 2011.

52. Harrold LR, Salman C, Shoor S, et al. Incidence and prevalence of juvenile idiopathic arthritis among children in a managed care population, 19962009. J Rheumatol. 2013;40(7):1218-25.

53. Biaggioni I, Freeman R, Mathias CJ, Low P, Hewitt LA, Kaufmann H. Randomized withdrawal study of patients with symptomatic neurogenic orthostatic hypotension responsive to droxidopa. Hypertension. 2014: HYPERTENSIONAHA. 114.04035.

54. Hibi T, Imai Y, Senoo A, Ohta K, Ukyo Y. Efficacy and safety of golimumab 52-week maintenance therapy in Japanese patients with moderate to severely active ulcerative colitis: a phase 3, double-blind, randomized, placebo-controlled study-(PURSUIT-J study). J Gastroenterol. 2017;52(10): $1101-11$.

55. Ruperto N, Brunner HI, Lovell DJ, Martini A. Extrapolation or controlled trials in paediatrics: the current dilemma. Archives of disease in childhood. 2017: archdischild-2017.

56. Ruperto N, Quartier P, Wulffraat N, et al. A phase II, multicenter, open-label study evaluating dosing and preliminary safety and efficacy of canakinumab in systemic juvenile idiopathic arthritis with active systemic features. Arthritis Rheum. 2012;64(2):557-67.

57. Yokota S, Miyamae T, Imagawa T, et al. Therapeutic efficacy of humanized recombinant anti-interleukin-6 receptor antibody in children with systemic-onset juvenile idiopathic arthritis. Arthritis Rheumatol. 2005;52(3):818-25.

58. PRCSG / PRINTO. Joint Assessor certification. https://prcsg.org/index.php/ prcsg-printo-joint-assessor-certification. Accessed 2 Jan 2018.

59. Yeung RS, Albani S, Feldman BM, Mellins E, Prakken B, Wedderburn LR. Enhancing translational research in paediatric rheumatology through standardization. Nat Rev Rheumatol. 2016;12(11):684-90.

60. Brachat $\mathrm{AH}$, Grom AA, Wulffraat $\mathrm{N}$, et al. Early changes in gene expression and inflammatory proteins in systemic juvenile idiopathic arthritis patients on canakinumab therapy. Arthritis Res Ther. 2017;19(1):13.

61. Nielsen S, Ruperto N, Gerloni V, et al. Preliminary evidence that etanercept may reduce radiographic progression in juvenile idiopathic arthritis. Clin Exp Rheumatol. 2008;26(4):688-92.

62. Simonini G, Giani T, Stagi S, de Martino M, Falcini F. Bone status over 1 yr of etanercept treatment in juvenile idiopathic arthritis. Rheumatology (Oxford). 2005;44(6):777-80.

63. Ruperto N, Lovell DJ, Li T, et al. Abatacept improves health-related quality of life, pain, sleep quality, and daily participation in subjects with juvenile idiopathic arthritis. Arthritis Care Res. 2010;62(11):1542-51.
64. Lovell DJ, Ruperto N, Mouy R, et al. Long-term safety, efficacy, and quality of life in patients with juvenile idiopathic arthritis treated with intravenous Abatacept for up to seven years. Arthritis Rheumatol. 2015; 67(10):2759-70

65. De Benedetti F, Brunner H, Ruperto N, et al. Catch-up growth during tocilizumab therapy for systemic juvenile idiopathic arthritis: results from a phase III trial. Arthritis Rheumatol. 2015;67(3):840-8.

\section{Ready to submit your research? Choose BMC and benefit from:}

- fast, convenient online submission

- thorough peer review by experienced researchers in your field

- rapid publication on acceptance

- support for research data, including large and complex data types

- gold Open Access which fosters wider collaboration and increased citations

- maximum visibility for your research: over $100 \mathrm{M}$ website views per year

At BMC, research is always in progress.

Learn more biomedcentral.com/submissions 